\title{
Microbial competition between Escherichia coli and Candida albicans reveals a soluble fungicidal factor
}

\author{
Damien J. Cabral ${ }^{1}$, Swathi Penumutchu ${ }^{1}$, Colby Norris ${ }^{1,2}$, Jose Ruben Morones-Ramirez ${ }^{3,4, *}$ and Peter \\ Belenky ${ }^{1, *}$ \\ ${ }^{1}$ Department of Molecular Microbiology and Immunology, Division of Biology and Medicine, Brown University, Providence, RI, \\ 02912, USA. \\ 2 Bryant University, Smithfield, RI, 02917 USA. \\ ${ }^{3}$ Universidad Autónoma de Nuevo León, Facultad de Ciencias Químicas, Pedro de Alba, S/N, San Nicolás de los Garza, Nuevo León, \\ México. \\ ${ }^{4}$ Centro de Investigacion en Biotecnologia y Nanotecnologia, Universidad Autonoma de Nuevo Leon, Facultad de Ciencias Quimicas, \\ Parque de Investigacion e Innovacion Tecnologica, Km. 10 autopista al Aeropuerto Internacional Mariano Escobedo, Apodaca, Nuevo \\ Leon. 66629. \\ * Corresponding Authors: \\ Peter Belenky, Ph.D., Assistant Professor of Molecular Microbiology and Immunology, Brown University, 171 Meeting Street,
} Providence, Rhode Island 02912, USA, 401 863-5954; E-mail: peter_belenky@brown.edu; Jose Ruben Morones-Ramirez, Universidad Autónoma de Nuevo León, Facultad de Ciencias Químicas, Pedro de Alba, S/N, San Nicolás de los Garza, Nuevo León, México; E-mail: jose.moronesrmr@uanl.edu.mx

ABSTRACT Localized and systemic fungal infections caused by Candida albicans can lead to significant mortality and morbidity. However, severe C. albicans infections are relatively rare, occurring mostly in the very young, the very old, and immunocompromised individuals. The fact that these infections are rare is interesting because as much as $\mathbf{8 0}$ percent of the population is asymptomatically colonized with $C$. albicans. It is thought that members of the human microbiota and the immune system work in concert to reduce C. albicans overgrowth through competition and modification of the growth environment. Here, we report that Escherichia coli (strain MG1655) outcompetes and kills $C$. albicans (strain SC5314) in vitro. We find that E. coli produces a soluble factor that kills $C$. albicans in a magnesium-dependent fashion such that depletion of available magnesium is essential for toxicity. doi: 10.15698/mic2018.05.631

Received originally: 15.12.2017;

In revised form: 21.02.2018,

Accepted 22.02.2018,

Published 07.03.2018.

Keywords: microbial competition, Escherichia coli, Candida albicans, antifungal, magnesium.

\section{Abbreviations:}

$L A B$ - lactic acid-producing bacteria.

\section{INTRODUCTION}

In order to combat the spread of antifungal resistance, we need to develop novel therapeutics to maintain our advantage over fungal infections. Microbial competition experiments have been an important tool for the discovery of novel antimicrobials since the work of Alexander Fleming, and the use of the "Waksman platform" to identify streptomycin and neomycin. These experiments can also provide important insight into the ways that microbial competition shape a healthy human microbial flora [1]. The human flora consists of bacteria, fungi, viruses, and some parasitic eukaryotes [2]. It is thought that this complex community and the interactions within it have coevolved to maintain relative homeostasis [2]. In most cases, the human microbiota is a net benefit to the host, aiding in processes ranging from nutrition to protection from infection. Thus, the disruption of the healthy microbial commu- nity, termed dysbiosis, is associated with numerous negative health outcomes, including Candida overgrowth [3-5].

The nature of microbial interactions that maintain a healthy microbiota has been the subject of significant research since the turn of the twentieth century [6]. We now understand that interactions within this community can be very complex, ranging from cooperation to predation $[7,8]$. Significant work has also been done to identify interactions between commensal bacteria and fungal pathogens. For example, recent studies have indicated that Staphylococcus aureus mucosal infection is promoted via an interaction with invasive C. albicans hyphae [9]. Similarly, Candida colonization of the respiratory tract may promote Pseudomonas aeruginosa infections in susceptible individuals [10, 11]. Interestingly $P$. aeruginosa has the opposite effect in vitro, interacting with fungal filaments to induce fungal death through the production of phenazine derivatives [12, 
13]. C. albicans also forms mutually beneficial biofilms with a variety of pathogens and commensal bacteria, which increases pathogenicity while also providing bacteria protection from the host and antimicrobials $[1,9,13]$. These polymicrobial communities may help commensal bacteria, but they can also promote fungal pathogenesis. For example, E. coli can contribute to bladder colonization and infection by $C$. albicans [14].

Not all C. albicans-bacteria interactions are mutually beneficial. In multiple examples, colonization with specific bacterial species has been shown to reduce Candida load and pathogenesis. Perhaps the most commonly used examples are vaginal and oral lactobacilli providing protection from vaginal and oral candidiasis, respectively [15]. In fact, this is a somewhat controversial assessment, and the in vitro and in vivo data are inconclusive. Some studies indicate that $\mathrm{pH}$ reduction associated with lactic acidproducing bacteria (LAB) inhibits $C$. albicans growth in vitro $[16,17]$, while other epidemiological studies do not show a significant correlation between LAB load and a reduction in fungal colonization or pathogenesis [1]. Evidence from studies testing the probiotic impact of LAB-usually Lactobacillus gasseri and related species-is also mixed, with some studies showing robust protection from candidiasis and others showing no improvement over control or placebo $[4,15,18,19]$.

In addition to the potential anti-Candida activity of lactobacilli, there is some evidence that enteric bacteria such as $E$. coli can be antifungal. The E. coli probiotic strain Nissle 1917 (serovar 06:K5:H1) provides protection from numerous pathogens in vitro, including $C$. albicans [20]. It is thought that this protection results from the immunomodulatory activity of Nissle, although this assumption has not been directly tested [21-23]. In addition to Nissle, several other $E$. coli strains have been found to inhibit C. albicans [24]. Hummel et al. performed both in vitro and in vivo studies, finding that naturally occurring $E$. coli strains can not only inhibit fungal colonization, but also induce a zone of inhibition on a Candida lawn. This result indicates that the anti-Candida activity of $E$. coli may utilize a soluble factor in addition to immunomodulation. Other studies have also found that $E$. coli and its lipopolysaccharide can modulate fungal growth and biofilms in vitro [25, 26]. Together, this work indicates that $E$. coli could inhibit and possibly kill $C$. albicans during a polymicrobial interaction. To decipher this interaction, we chose to co-culture $E$. coli (strain MG1655) and C. albicans (strain SC5314) in vitro. We found that $E$. coli rapidly kills $C$. albicans via a soluble factor in a manner that is inversely dependent on the availability of magnesium.

\section{RESULTS AND DISCUSSION}

To define the interaction between E. coli and C. albicans in vitro, we cultured both organisms as monocultures and coculture in YPD medium at $37^{\circ} \mathrm{C}$ with vigorous shaking. Serial dilutions of the cultures were plated on solid YPD supplemented with ampicillin to quantitate $C$. albicans and solid LB supplemented with amphotericin B to quantitate $E$. coli. We found that E. coli grew equally well in the presence and absence of $C$. albicans (Figure 1A). Conversely, C. albicans growth was impacted by $E$. coli co-culture when compared to $C$. albicans grown alone, showing growth inhibition by six hours (Figure 1B). Interestingly, the number of viable Candida cells began to decrease after six hours of culture and was eventually reduced 5000 -fold by 16 hours when compared to the six-hour time point. This result indicates that $E$. coli is not only inhibitory of $C$. albicans but also robustly fungicidal. To determine whether fungal cell numbers or growth phase was important for fungicidal activity, we delayed the addition of $E$. coli until 6 hours after the initiation of Candida culture - about the time $C$. albicans reaches maximum density. We found that the bacteria had a robust fungicidal effect even when the E. coli was added to fully dense fungal culture, reducing fungal counts by approximately 1500 -fold from the maximum density (Figure 1B). This indicates that $E$. coli can induce fungal death even in dense culture and demonstrates that $E$. coli has robust fungicidal activity.

Our data indicate that $E$. coli can induce conditions that lead to fungal death during in vitro co-culture with

\section{A}
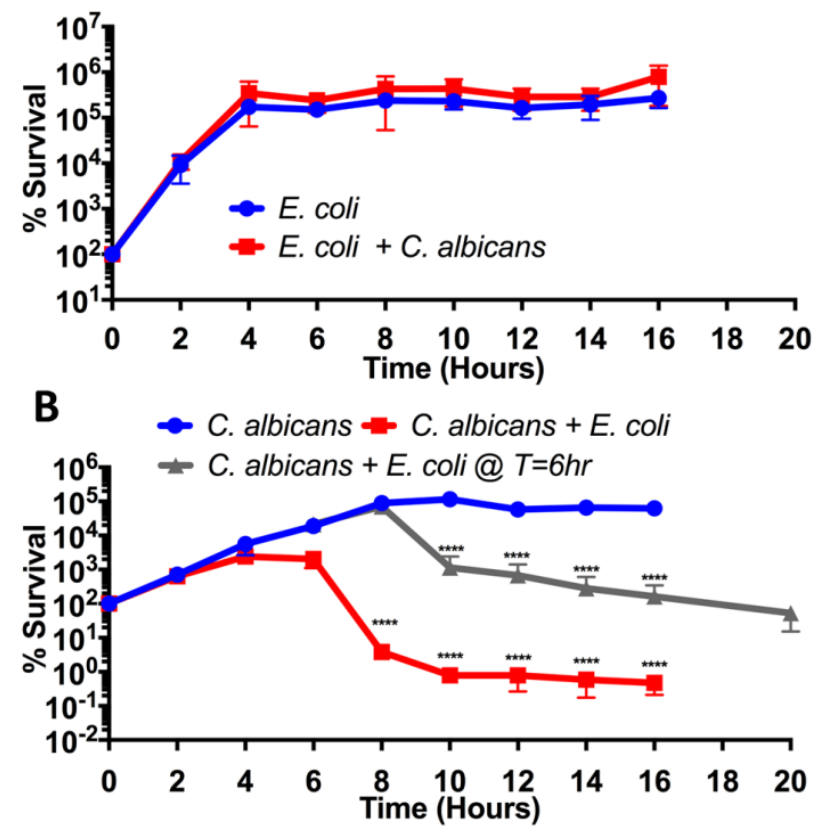

FIGURE 1: $\boldsymbol{E}$. coli kills $\boldsymbol{C}$. albicans in culture. (A) Percent survival of E. coli cultured alone or in co-culture with C. albicans. (B) Percent survival of $C$. albicans cultured alone or in co-culture with $E$. coli added at $\mathrm{T}=0$ hours or at $\mathrm{T}=$ six hours. Data shown reflect mean \pm $\mathrm{SD}$ of $\mathrm{n}=3$. Statistical significance was calculated using a two-way ANOVA in Prism 7.0. For each time point, both $C$. albicans $+E$. coli media types were compared to the $C$. albicans media control. $\mathrm{P}$ values were subsequently corrected for multiple comparisons using the Bonferroni method. $* * * *$ denotes an adjusted $\mathrm{p}$-value of less than 0.0001 . No time points were found to be statistically significant in Figure $1 \mathrm{~A}$. 
C. albicans. This phenotype can result from close interaction between bacterial cells and fungal cells, as is seen in the case of Candida and P. aeruginosa [12], or from the production of a fungicidal compound. To test whether E. coli produces a toxic soluble factor, we collected conditioned media at six hours from $C$. albicans and E. coli monocultures and from the co-culture. The respective conditioned media were filtered and buffered with PBS ( $\mathrm{pH} 7.4)$ prior to the addition of fresh log-phase $C$. albicans cells. We found that over a 16-hour experiment, cells grown in C. albicans conditioned media did not display a reduction in colony forming units (CFU). On the other hand, E. coli conditioned media and media from the co-culture induced a 100 -fold drop in viable CFUs (Figure 2A). We also found that media from the co-culture was somewhat more toxic than media from $E$. coli alone, although the difference was not consistently statistically significant. These results indicate that $E$. coli secretes a powerful fungicidal element and that its production may not be significantly stimulated by the presence of $C$. albicans.

To further explore the impact of conditioned media on fungal death, we conducted additional endpoint experiments that quantified fungal viability after 16 hours (Figure 2B). If fungal toxicity in conditioned media resulted from the presence of a soluble factor, we would anticipate that the toxic activity would dissipate with dilution. We found that diluting the co-culture conditioned media with PBS did not significantly impact toxicity at a 1:2 dilution and at a 1:10 dilution (Figure 2B). However, the 1:100 dilution completely abolished fungicidal activity, indicating that the E. coli-produced factor behaves as a dilutable molecule. Next, we sought to test the thermal stability of the fungicidal activity by boiling the co-culture conditioned media for ten minutes prior to testing fungicidal activity. We found that boiling reduces fungicidal activity by an order of magnitude but did not completely abolish it, indicating that the fungicidal molecule is relatively heat stable. Other studies have indicated that bacteria can produce bacteriocins like fungicidal peptides $[27,28]$. We suspect that $E$. coli could be producing a similar fungicidal peptide. We exposed co-culture conditioned media to proteinase $\mathrm{K}$ (Pro K) digestion for 2 hours at $56^{\circ} \mathrm{C}$. This treatment did not reduce antifungal activity, indicating that the secreted molecule is insensitive to Pro $\mathrm{K}$ under the tested conditions (Figure 2 B). However, this is not a conclusive indication that the antifungal molecule is not a peptide. It is possible that Pro $\mathrm{K}$ activity was inhibited by conditioned media components or that the peptide sequence/structure is not cleavable by Pro $\mathrm{K}$.

During this work, we noticed reduced fungicidal activity when the co-culture was conducted in different batches of YPD powder purchased from Fisher Scientific. While this result was rare, it indicated that media content might play a role in the competitive interaction and fungicidal toxicity of the produced factor. YPD is not a defined media, thus some variability is possible from batch to batch. However, yeast nitrogen base (YNB), typically used to make synthetic dextrose complete (SDC) media, is defined, containing set concentrations of vitamins, metals, and trace elements
A

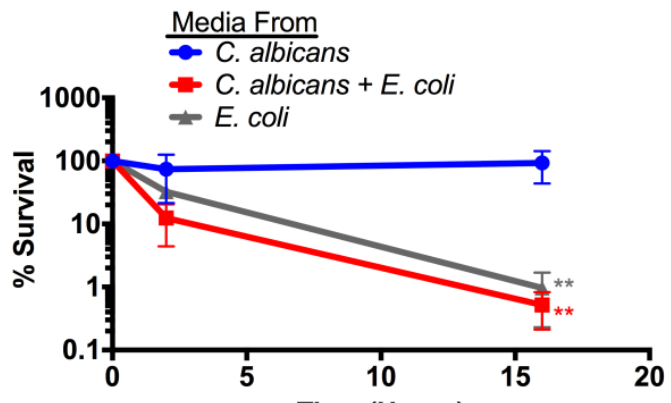

B
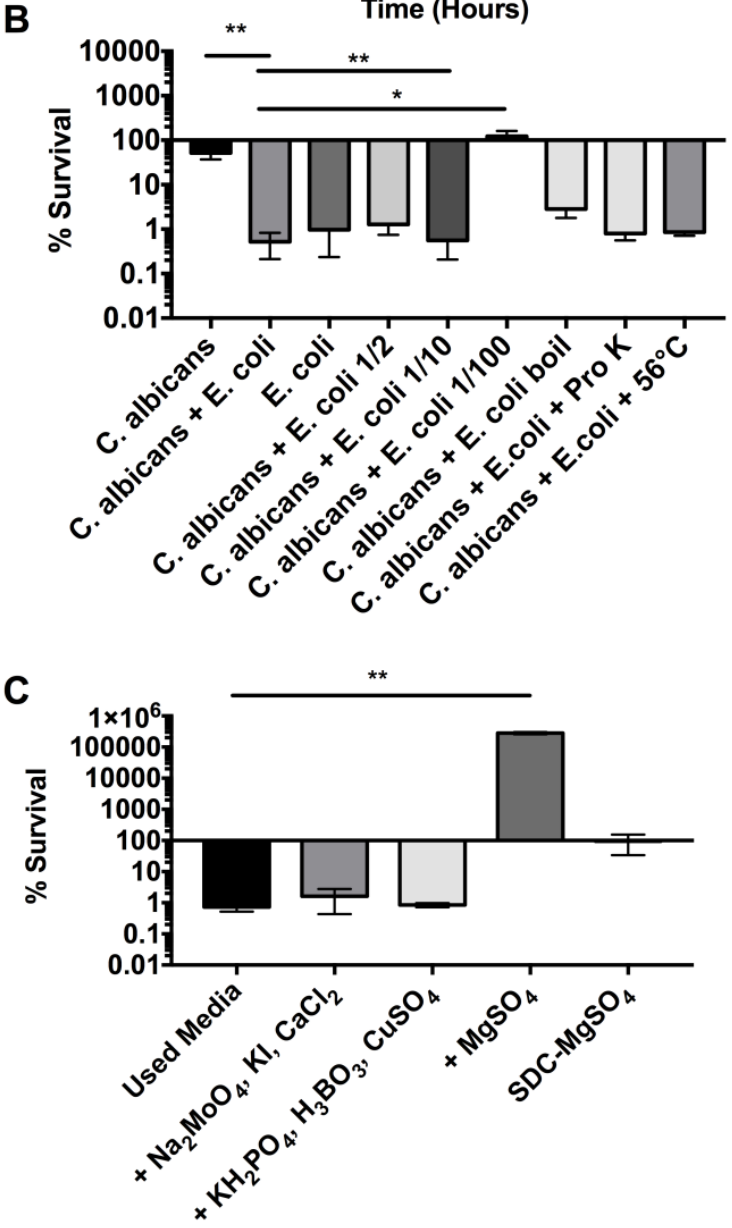

FIGURE 2: $E$. coli produces a soluble fungicidal molecule. (A) Percent survival of $C$. albicans cultured in the indicated conditioned media collected after 6 hours of co-culture. Statistical significance was calculated using an unpaired two-tailed t-test in which the $E$. coli and the $C$. albicans $+E$. coli medias were compared to the $C$. albicans media control. (B) Percent survival of $C$. albicans cultured in the indicated conditioned media for 16 hours. Statistical significance was calculated using a one-way ANOVA in Prism 7.0. P-values were subsequently corrected for multiple comparisons using the Bonferroni method. All conditions were compared to the $C$. albicans media control. (C) Percent survival of $C$. albicans cultured in $E$. coli $+C$. albicans conditioned media for 16 hours. Compounds were added at the concentrations consistent with standard YNB [Boric acid $(0.5 \mathrm{mg} / \mathrm{L})$, Copper (II) sulfate pentahydrate $(0.04 \mathrm{mg} / \mathrm{L})$ Sodium molybdate $(0.2 \mathrm{mg} / \mathrm{L})$, Potassium iodide $(0.1 \mathrm{mg} / \mathrm{L})$, Calcium chloride dihydrate $(100 \mathrm{mg} / \mathrm{L})$, Potassium phosphate monobasic anhydrous (1000 mg/L) and Magnesium sulfate anhydrous (500 mg/L)]. Statistical significance was calculated using a one-way ANOVA in Prism 7.0 to compare all conditions to the used media control. P-values were subsequently corrected for multiple comparisons using the Bonferroni method. Statistical significance is shown $(* p>0.05 ; * * p>0.01 * * * p>0.001)$. 
that are essential for fungal growth. Since metals and trace elements are most likely to be limiting in growth media, we chose to focus on these molecules. To test the impact of metals and trace elements on toxicity, we added either single compounds or mixtures of compounds at concentrations found in YNB to our conditioned co-culture media. We found that the addition of magnesium alone was sufficient to disrupt all fungicidal activity and actually restore fungal growth in previously toxic conditioned media. This result may seem to indicate that magnesium limitation is the cause of the toxicity. However, this is not the case because Figure $1 \mathrm{~B}$ demonstrates that the toxicity is dilutable and heat labile. If magnesium limitation were the sole cause of toxicity, we would anticipate that dilution of conditioned media would enhance fungicidal activity rather than abolish it. Additionally, when $C$. albicans was grown in media lacking magnesium (SDC - Mg), we observed growth arrest but not toxicity (Figure $2 \mathrm{C}$ ). While these results do not indicate that magnesium limitation is the cause of toxicity, they do indicate that efficient killing requires magnesium limitation.

To further explore the impact of magnesium on toxicity, we titrated varying amounts of $\mathrm{MgSO}_{4}$ into co-culture conditioned media. We found that the addition of magnesium begins to reduce toxicity at concentrations above $15 \mu \mathrm{M}$ and promotes growth after $125 \mu \mathrm{M}$ (Figure 3A). This indicates that magnesium limitation may be the cause of $C$. albicans growth limitation in YPD. To quantify magnesium levels in conditioned media at multiple time points, we utilized a colorimetric magnesium assay kit (MAK026 SIGMA). We found that in a YPD C. albicans-E. coli co-culture, magnesium levels are completely depleted by four hours (Figure 3B) - a time that coincides with the first detectable toxicity during co-culture (Figure 1B). The depletion of magnesium by $C$. albicans alone displayed different kinetics but was also complete by five hours. This result supports our assessment that magnesium depletion alone is not sufficient to induce toxicity because we found that conditioned media collected from a $C$. albicans monoculture was not toxic despite the complete depletion of magnesium by six hours (Figure 3B). Finally, we found that magnesium levels drop rapidly but do not fall below $60 \mu \mathrm{M}$ in the $E$. coli monoculture. This may explain the slightly reduced toxicity of $E$. coli conditioned media when compared to the co-culture.

Next, we tested the impact of ethylenediaminetetraacetic acid (EDTA), a magnesium chelator, on the toxicity of conditioned media. We found that the addition of EDTA did not have a statistically significant impact on the toxicity of the co-culture conditioned media. However, it did have a significant impact on the toxicity of $E$. coli monoculture media, restoring it to the same toxicity as the co-culture media. Combined with results from Figure $3 B$ this observation may indicate that chelating the remaining magnesium in the $E$. coli media promoted toxicity, further supporting the role of magnesium depletion in $E$. coli-mediated killing of $C$. albicans. However, because EDTA can also chelate
A

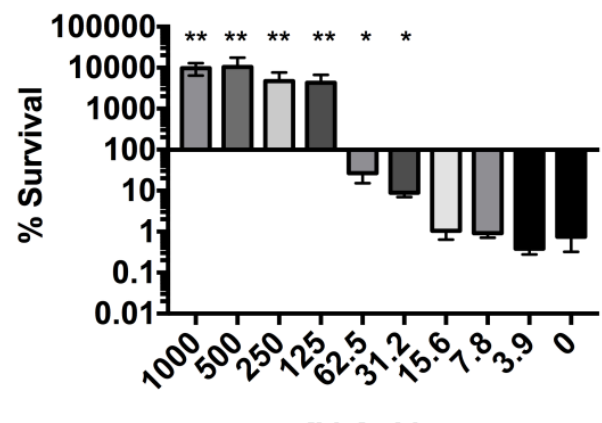

B
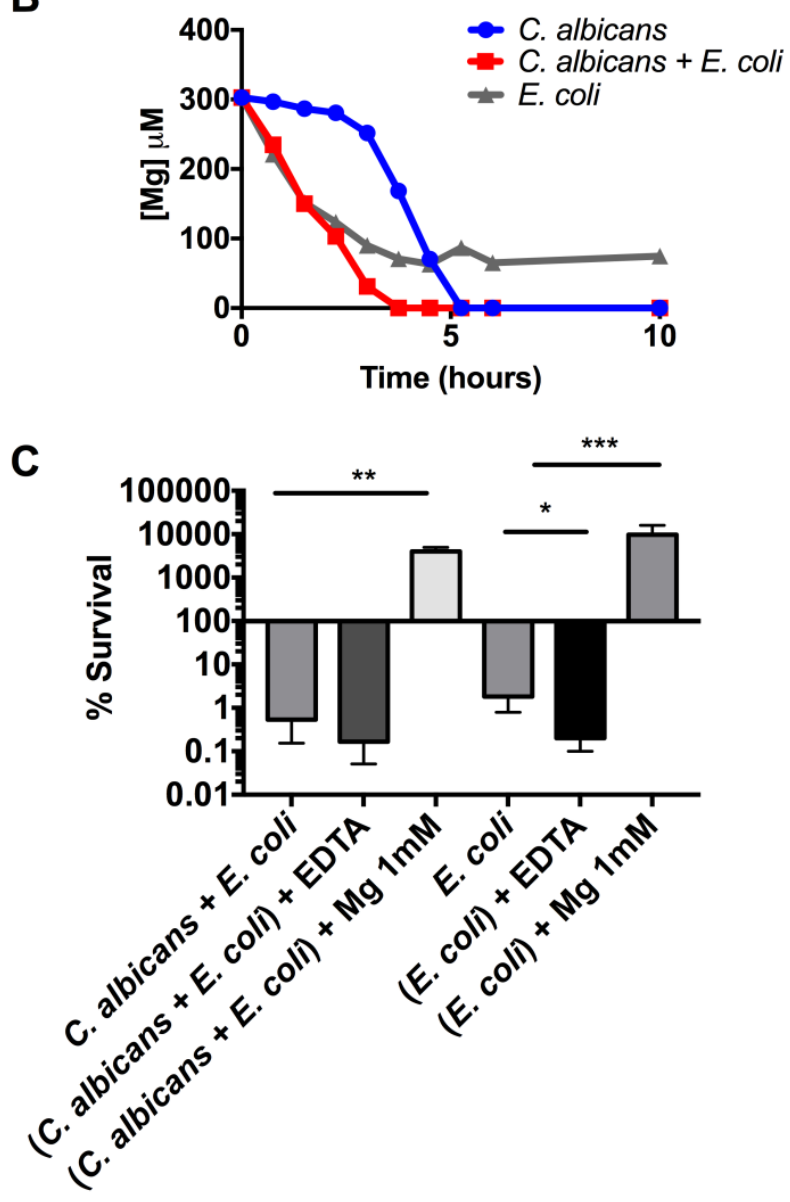

FIGURE 3: $E$. coli toxicity depends on magnesium limitation. (A) Percent survival of C. albicans cultured in $E$. coli $+C$. albicans conditioned media with the indicated concentrations of added $\mathrm{MgSO}_{4}$. To calculate statistical significance, percent survivals were first $\log _{10}$ normalized to stabilize variances. Paired, two tailed $t$ tests were performed to compare every condition to the negative control $(0 \mu \mathrm{M})$. (B) Quantified magnesium concentration in condition media. (C) Percent survival of $C$. albicans cultured in the indicated conditioned media for 16 hours. EDTA was added at $500 \mu \mathrm{M}$ final concentration. Data shown reflect mean $\pm S D$ of $n=3$. Statistical significance was calculated using a paired two-tailed t-test $(* p>0.05 ; * * p>0.01 * * * p>0.001)$. 
other divalent ions, such as calcium, we must also consider the possibility that these other ions may play a role.

\section{CONCLUSION}

In this work, we found that $E$. coli kills $C$. albicans when cocultured in vitro. We assert that this activity results from a soluble factor produced by $E$. coli in a manner that is independent of the presence of fungal cells. We also found that magnesium limitation is required for the observed toxicity. While we hope that this work can lead to the identification of novel antifungal therapeutics in the future, we are also cognizant that the requirement of magnesium limitation may somewhat limit the therapeutic use or clinical relevance of our discovery. The total magnesium in human serum ranges from between 1000 and $500 \mu \mathrm{M}$ [29]. This is significantly higher than the maximum concentration under which we see toxicity in vitro. This indicates that if the toxic E. coli-C. albicans interactions were to occur in vivo, they would need to happen in microenvironments within the host where magnesium concentrations are naturally lower or depleted by fungal or bacterial growth; however, we envision that local conditions in the host are sufficient to deplete magnesium, promote interactions between $E$. coli and C. albicans, and induce the observed fungicidal activity.

We view this work as a critical first step in defining the identified competitive interaction between Candida and E. coli. The next steps should involve the fractionation of conditioned media for the identification of the active compound and the screening of $E$. coli knockouts to identify genes required for its production. Perhaps the most important and interesting observation presented here is the role of magnesium limitation in toxicity. Thus, explaining this observation could be the most interesting next step. We hypothesize that three potential factors could explain this observation. First, the toxic compound produced by $E$. coli may only be active on non-growing fungal cells and thus magnesium limitation promotes toxicity by blocking fungal growth. Second, the compound may require active import that is induced by magnesium restriction. Finally, the compound may be inhibited by magnesium binding. By identifying how magnesium regulates toxicity, we may find methodologies that maintain toxicity under physiological conditions.

Based on magnesium ion sensitivity and heat instability, we suspect that the detected antifungal activity is likely caused by a peptide. Bacteria produce a wide array of antimicrobial bacteriocin peptides and bacteriocin-like extracellular metabolites to control surrounding microbial populations [30, 31]. Some of these bacteriocins can also display significant antifungal activity $[27,28,32]$. Like other bacteria, E. coli also produces multiple bacteriocins, including colicins and microcins [33, 34]. While these are mostly antibacterial in nature, it is possible that bacteriocins produced by $E$. coil under our experimental conditions have antifungal properties. Most intriguingly, some studies indicate that bacteriocin toxicity is impacted by divalent cations such as magnesium. For example, the antimicrobial activity of a bacteriocin from Streptococcus sanguinis is accentuated with decreasing external concentrations of $\mathrm{Ca}^{2+}$ [30]. In other cases, antimicrobial properties are increased when $\mathrm{Ca}^{2+}, \mathrm{Fe}^{+3}$ and $\mathrm{Mg}^{+2}$ concentrations are increased [35-37]. Thus, the modulation of bacteriocin activity by divalent cation concentrations presents a possible connection to our observed magnesium results.

\section{MATERIALS AND METHODS}

Co-culture experiments were conducted in YPD incubated at $300 \mathrm{rpm}$ and $37^{\circ} \mathrm{C}$. YPD liquid medium was sterilized by filtration rather than autoclaving to preserve nutritional content. Overnight fungal cultures of $C$. albicans (strain SC5314) were diluted to an $\mathrm{OD}_{600}$ of 0.07 and allowed to grow to an $\mathrm{OD}_{600}$ of 0.2 . Overnight cultures of $E$. coli (strain MG1655) were grown in LB and were subsequently diluted 1:200 into fresh YPD and allowed to grow to an $\mathrm{OD}_{600}$ of 0.2 . When both fungal and bacterial cultures reached 0.2 , they were centrifuged and resuspended in fresh YPD. Final culture experiments were started in $250 \mathrm{~mL}$ flasks ( $25 \mathrm{~mL}$ of culture) with C. albicans diluted to an $\mathrm{OD}_{600}$ of 0.1 and $E$. coli diluted to 0.001 . Over the next 16 to 20 hours, CFUs were measured by plating eight serial dilutions onto YPD agar plates with $100 \mu \mathrm{g} / \mathrm{mL}$ of ampicillin (to detect C. albicans) and on LB with $100 \mu \mathrm{g} / \mathrm{mL}$ of amphotericin $\mathrm{B}$ (to detect $E$. coli). CFU/mL was converted to percent survival for analysis.

Conditioned media was made by filtering growth media through a 0.2-micron filter and by adding PBS ( $\mathrm{pH} 7.4$ ) to a final concentration of $0.1 X$. The final solution was stored for up to two weeks at $4^{\circ} \mathrm{C}$. Conditioned media experiments were initiated by diluting PBS-washed log-phase $C$. albicans into $0.5 \mathrm{~mL}$ of conditioned media to an $\mathrm{OD}_{600}$ of 0.1 . Kill curves were conducted in 24-well plates incubated at $300 \mathrm{rpm}$ and $37^{\circ} \mathrm{C}$. CFUs were again measured by plating eight serial dilutions onto YPD agar plates.

Pro $\mathrm{K}$ treatment was conducted by incubating conditioned media buffered with $0.1 \mathrm{X}$ PBS with $100 \mu \mathrm{g} / \mathrm{mL}$ of Pro K (NEB) for two hours at $56^{\circ} \mathrm{C}$. Magnesium was quantitated in conditioned media using a colorimetric magnesium assay kit (MAK026 SIGMA) according to manufacturer's instructions.

\section{ACKNOWLEDGEMENTS}

This work was supported by grant number P20GM103430 from the National Institute of General Medical Sciences of the National Institutes of Health through the IDeA Network of Biomedical Research (INBRE) program and by the basic science grant 221332 from CONACYT. Additional support was provided by grants from the National Science Foundation Graduate Research Fellowship (Grant No. 1644760) and the Center for Computational Biology of Human Disease (NIH P20 GM109035). Finally, additional funding was provided by the Paicyt 2016-2017 Science Grant from the Universidad Autónoma de Nuevo León and the Fronteras de la Ciencia grant 1502 and Infraestructura Grant 279957 from CONACYT. We would also like to thank Dr. James Collins (Massachusetts Institute of Technology) for his guidance and advice on this project.

\section{CONFLICT OF INTEREST}

The authors have no conflicts of interest to report. 


\section{COPYRIGHT}

(C) 2018 Cabral et al. This is an open-access article released under the terms of the Creative Commons Attribution (CC BY) license, which allows the unrestricted use, distribution, and reproduction in any medium, provided the original author and source are acknowledged.

\section{REFERENCES}

1. Shirtliff ME, Peters BM, and Jabra-Rizk MA (2009). Crosskingdom interactions: Candida albicans and bacteria. FEMS Microbiol Lett 299(1): 1-8. doi: 10.1111/j.1574-6968.2009.01668.x

2. Consortium THMP (2012). Structure, function and diversity of the healthy human microbiome. Nature 486(7402): 207-214. doi: 10.1038/nature11234

3. Collins SM (2014). A role for the gut microbiota in IBS. Nat Rev Gastroenterol Hepatol 11(8): 497-505. doi: 10.1038/nrgastro.2014.40

4. Kraft-Bodi E, Jørgensen MR, Keller MK, Kragelund C, and Twetman S (2015). Effect of Probiotic Bacteria on Oral Candida in Frail Elderly. J Dent Res 94(9 Suppl): 181S-6S. doi: $10.1177 / 0022034515595950$

5. Cabral DJ, Wurster JI, Flokas ME, Alevizakos M, Zabat M, Korry BJ, Rowan AD, Sano WH, Andreatos N, Ducharme RB, Chan PA, Mylonakis E, Fuchs BB, and Belenky P (2017). The salivary microbiome is consistent between subjects and resistant to impacts of short-term hospitalization. Sci Rep 7(1): 11040. doi: 10.1038/s41598-017-11427-2

6. Sonnenborn U (2016). Escherichia coli strain Nissle 1917-from bench to bedside and back: history of a special Escherichia coli strain with probiotic properties. FEMS Microbiol Lett 363(19): fnw212. doi: 10.1093/femsle/fnw212

7. Coyte KZ, Schluter J, and Foster KR (2015). The ecology of the microbiome: Networks, competition, and stability. Science 350(6261): 663-666. doi: 10.1126/science.aad2602

8. Vazquez-Rodriguez A, Vasto-Anzaldo XG, Barboza Perez D, Vázquez-Garza E, Chapoy-Villanueva H, García-Rivas G, GarzaCervantes JA, Gómez-Lugo JJ, Gomez-Loredo AE, Garza Gonzalez MT, Zarate X, Morones-Ramirez JR (2018). Microbial Competition of Rhodotorula mucilaginosa UANL-001L and E. coli increase biosynthesis of Non-Toxic Exopolysaccharide with Applications as a Wide-Spectrum Antimicrobial. Sci Rep 8(1):798. doi: 10.1038/s41598-017-17908-8

9. Schlecht LM, Peters BM, Krom BP, Freiberg JA, Hänsch GM, Filler SG, Jabra-Rizk MA, and Shirtliff ME (2015). Systemic Staphylococcus aureus infection mediated by Candida albicans hyphal invasion of mucosal tissue. Microbiology 161(1): 168-181. doi: 10.1099/mic.0.083485-0

10. Azoulay E, Timsit JF, Tafflet $M$, de Lassence A, Darmon $M$, Zahar JR, Adrie C, Garrouste-Orgeas M, Cohen Y, Mourvillier B, Schlemmer B, Outcomerea Study Group (2006). Candida Colonization of the Respiratory Tract and Subsequent Pseudomonas Ventilator-Associated Pneumonia. Chest 129(1): 110-117. doi: 10.1378/chest.129.1.110

11. Nseir S, Jozefowicz E, Cavestri B, Sendid B, Di Pompeo C, Dewavrin F, Favory R, Roussel-Delvallez M, and Durocher A (2006) Impact of antifungal treatment on Candida-Pseudomonas interaction: a preliminary retrospective case-control study. Intensive Care Med 33(1): 137-142. doi: 10.1007/s00134-006-0422-0
Please cite this article as: Damien J. Cabral, Swathi Penumutchu, Colby Norris, Ruben Morones-Ramirez and Peter Belenky (2018). Microbial competition between Escherichia coli and Candida albicans reveals a soluble fungicidal factor. Microbial Cell 5(5): 249-255. doi: 10.15698/mic2018.05.631

12. Gibson J, Sood A, and Hogan DA (2009). Pseudomonas aeruginosa-Candida albicans interactions: localization and fungal toxicity of a phenazine derivative. Appl Environ Microbiol 75(2): 504-513. doi: 10.1128/AEM.01037-08

13. Peleg AY, Hogan DA, and Mylonakis E (2010). Medically important bacterial-fungal interactions. Nat Rev Microbiol 8(5): 340-349. doi: 10.1038/nrmicro2313

14. Levison ME, and Pitsakis PG (1987). Susceptibility to experimental Candida albicans urinary tract infection in the rat. J Infect Dis 155(5): 841-846. PMID: 3549921

15. Tachedjian G, Aldunate M, Bradshaw CS, and Cone RA (2017). The role of lactic acid production by probiotic Lactobacillus species in vaginal health. Res Microbiol 168(9-10):782-792. doi: 10.1016/j.resmic.2017.04.001

16. Juárez Tomás MS, Saralegui Duhart $\mathrm{Cl}$, De Gregorio PR, Vera Pingitore $E$, and Nader-Macías ME (2011). Urogenital pathogen inhibition and compatibility between vaginal Lactobacillus strains to be considered as probiotic candidates. Eur J Obstet Gynecol Reprod Biol 159(2): 399-406. doi: 10.1016/j.ejogrb.2011.07.010

17. Krasner Ri, Young G, and Yudofsky PL (1956). Interactions of oral strains of Candida albicans and lactobacilli. J Bacteriol 72(4): 525-529. PMID: 13366958

18. Gil NF, Martinez RCR, Gomes BC, Nomizo A, and De Martinis ECP (2010). Vaginal lactobacilli as potential probiotics against Candida SPP. Braz J Microbiol 41(1): 6-14. doi: 10.1590/S151783822010000100002

19. Pendharkar S, Brandsborg E, Hammarström L, Marcotte $H$, and Larsson P-G (2015). Vaginal colonisation by probiotic lactobacilli and clinical outcome in women conventionally treated for bacterial vaginosis and yeast infection. BMC Infect Dis 13:1. 15(1): 255. doi: 10.1186/s12879-015-0971-3.

20. Preidis GA, and Versalovic J (2009). Targeting the human microbiome with antibiotics, probiotics, and prebiotics: gastroenterology enters the metagenomics era. Gastroenterology 136(6): 2015-2031. PMID: 19462507

21. Hockertz S (1997). Augmentation of host defence against bacterial and fungal infections of mice pretreated with the nonpathogenic Escherichia coli strain Nissle 1917. Arzneimittelforschung 47(6): 793-796. PMID: 9239462

22. Hafez M, Hayes K, Goldrick M, Warhurst G, Grencis R, and Roberts IS (2009). The K5 capsule of Escherichia coli strain Nissle 1917 is important in mediating interactions with intestinal epithelial cells and chemokine induction. Infect Immun 77(7): 29953003. doi: 10.1128/IAI.00040-09

23. Wehkamp J, Harder J, Wehkamp K, Wehkamp-von Meissner B, Schlee M, Enders C, Sonnenborn U, Nuding S, Bengmark S, Fellermann K, Schröder JM, and Stange EF (2004). NF-kappaB- and AP1-mediated induction of human beta defensin-2 in intestinal epithelial cells by Escherichia coli Nissle 1917: a novel effect of a 
probiotic bacterium. Infect Immun 72(10): 5750-5758. doi: 10.1128/IAI.72.10.5750-5758.2004

24. Hummel RP, Oestreicher EJ, Maley MP, and MacMillan BG (1973). Inhibition of Candida albicans by Escherichia coli in vitro and in the germfree mouse. J Surg Res 15(1): 53-58. doi: 10.1016/0022-4804(73)90163-7

25. Gale D, and Sandoval B (1957). Response of mice to the inoculations of both Candida albicans and Escherichia coli. I. The enhancement phenomenon. J Bacteriol 73(5): 616-624. PMID: 13428706

26. Bandara HMHN, Yau JYY, Watt RM, Jin LJ, and Samaranayake LP (2009). Escherichia coli and its lipopolysaccharide modulate in vitro Candida biofilm formation. J Med Microbiol 58(12): 16231631. doi: 10.1099/jmm.0.012989-0

27. Gerez CL, Torres MJ, Font de Valdez G, and Rollán G (2013). Control of spoilage fungi by lactic acid bacteria. Biological Control 64(3): 231-237. doi: 10.1016/j.biocontrol.2012.10.009

28. Kaewsrichan J, Peeyananjarassri K, and Kongprasertkit J (2006) Selection and identification of anaerobic lactobacilli producing inhibitory compounds against vaginal pathogens. FEMS Immunol Med Microbiol 48(1): 75-83. doi: 10.1111/j.1574695X.2006.00124.x

29. Longstreet $D$, and Vink R (2009). Correlation between total and ionic magnesium concentration in human serum samples is independent of ethnicity or diabetic state. Magnesium Research 22(1): 32-36. PMID: 19441272

30. Ma S, Zhao Y, Xia X, Dong X, Ge W, and Li H (2015). Effects of Streptococcus sanguinis Bacteriocin on Cell Surface Hydrophobicity, Membrane Permeability, and Ultrastructure of Candida Thallus. Biomed Res Int 2015(2): 514152-8. doi:

\section{$10.1155 / 2015 / 514152$}

31. Kommineni S, Bretl DJ, Lam V, Chakraborty R, Hayward M, Simpson P, Cao Y, Bousounis P, Kristich CJ, and Salzman NH (2015). Bacteriocin production augments niche competition by enterococci in the mammalian gastrointestinal tract. Nature 526(7575): 719-722. doi: 10.1038/nature15524

32. Zhao X, Zhou Z-J, Han Y, Wang Z-Z, Fan J, and Xiao H-Z (2013). Isolation and identification of antifungal peptides from Bacillus BH072, a novel bacterium isolated from honey. Microbiol Res 168(9): 598-606. doi: 10.1016/j.micres.2013.03.001

33. Rebuffat S (2011). Microcins from Enterobacteria: On the Edge Between Gram-Positive Bacteriocins and Colicins. Prokaryotic Antimicrobial Peptides. Springer, New York, N. pp 333-349. doi: 10.1007/978-1-4419-7692-5_17

34. Budič M, Rijavec M, Petkovšek Z, and Zgur-Bertok D (2011). Escherichia coli bacteriocins: antimicrobial efficacy and prevalence among isolates from patients with bacteraemia. PLOS ONE 6(12): e28769. doi: 10.1371/journal.pone.0028769

35. Ben-Shushan G, Zakin V, and Gollop N (2003). Two different propionicins produced by Propionibacterium thoenii P-127. Peptides 24(11): 1733-1740. doi: 10.1016/j.peptides.2003.08.018

36. Houlihan AJ, and Russell JB (2006). The Effect of Calcium and Magnesium on the Activity of Bovicin HC5 and Nisin. Curr Microbiol 53(5): 365-369. doi: 10.1007/s00284-005-0417-z

37. Oluwafemi Adedire, Omowumi Adegboye, Adebayo Osesusi (2015). Studies on the Mode of Action of Bacteriocin Produced by Lactobacillus fermentum CrT21. International Journal of Science and Research 5(5): 759-763. doi: 10.21275/v5i5.NOV163177 